\title{
Panicum maximum as a reservoir of a potential maize pathogen
}

\author{
N. C. Maia • M. P. Melo • S. S. C. Guimarães • K. S. \\ Matos • S. I. Moreira • U. G. P. Lana • P. G. Cardoso
}

Accepted: 22 October 2020 /Published online: 11 November 2020

(C) Koninklijke Nederlandse Planteziektenkundige Vereniging 2020

\begin{abstract}
Endophytic fungi are capable of infecting plants without inducing the development of any observable symptoms. Certain fungal species can also coexist as latent pathogens in their specific hosts. Several species of Fusarium have been reported to form an association with grasses as endophytes or latent pathogens, some of which are also mycotoxin producers. In this study, we aimed to address whether forage grasses could act as potential reservoirs of species that are pathogenic to maize (Zea mays). To this end, we performed morphological and phylogenetic analyses of the elongation factor $1-\alpha(E F-1 \alpha)$ and the second largest subunit of RNA polymerase II (RPB2) genes and characterized three fungal strains isolated from Panicum maximum (cv. Mombaça) as a new phylogenetic species, Fusarium gigantea, within the Fusarium fujikuroi species complex. Moreover, the results of the pathogenicity test,
\end{abstract}

Supplementary Information The online version contains supplementary material available at https://doi.org/10.1007 /s10658-020-02145-z.

N. C. Maia • P. G. Cardoso $(\bowtie)$

Departamento de Biologia, Universidade Federal de Lavras, Lavras, MG 37200-900, Brazil

e-mail: patricia@ufla.br

M. P. Melo

Universidade Federal do Acre, Campus Floresta, Cruzeiro do Sul, AC 68895-000, Brazil

S. S. C. Guimarães · S. I. Moreira

Departamento de Fitopatologia, Universidade Federal de Lavras, Lavras, MG 37200-900, Brazil such as the toothpick inoculation assay, revealed that these species caused the stalk rot disease in maize when maintained under greenhouse conditions. This finding highlights $P$. maximum as a potential reservoir of this pathogen and its role as a threat to maize cultivation.

Keywords Forage grass $\cdot$ Fusarium fujikuroi species complex $\cdot$ Molecular phylogeny $\cdot$ Maize disease

\section{Introduction}

Endophytic fungi colonize healthy plant tissues and affect their physiological functions by modulating the host plant's resistance mechanism. This is mediated by interactions such as hyperparasitism, competition or antibiosis (Busby et al. 2016). By definition, an 
endophyte cannot cause disease. However, depending on the host environment, a fungal endophyte might elicit pathogenicity. Therefore, to establish whether an endophytic fungus has the potential to elicit pathogenicity, further investigation is necessary to provide functional proof of endophyte pathogenicity that can validate Koch's postulates as well (Photita et al. 2004; Busby et al. 2016; Górzyńska et al. 2019).

Studies have revealed that several species of Fusarium are endophytic. However, some of them transform into aggressive pathogens upon exposure to environmental stress (Leslie and Summerell 2006). Several Fusarium species, including those belonging to the Fusarium fujikuroi species complex (FFSC), are associated with grasses from natural vegetation and cultivated species either as endophytes or as pathogens (Leslie et al. 2004). These include $F$. fujikuroi, an etiological agent of "bakanae" in rice, which forms an association with aquatic plants of the genus Echinochloa in rice-growing areas (Carter et al. 2008), and Fusarium circinatum, a causal agent of pitch canker of pine trees, which forms an association with wild grasses such as Holcus lanatus and Festuca arundinacea (Swett and Gordon 2012; Swett et al. 2014). Other examples include Fusarium sacchari, a predominant endophytic species colonizing Oryza australienses, which is also found to be pathogenic to maize, rice and sorghum (Petrovic et al. 2013); Fusarium konzum, which was found to be associated with Andropogon and Sorghastrum plants found in an ecological park in Kansas (Zeller et al. 2003); and Fusarium coicis and Fusarium tjaebata, found to be associated with wild grasses in Australia (Laurence et al. 2015).

In addition, certain species of FFSC, such as Fusarium verticillioides, Fusarium proliferatum, Fusarium thapsinum, Fusarium konzum, and Fusarium subglutinans, have also been shown to produce mycotoxins and were typically isolated from maize or sorghum crops as well as from North American prairie grasses (Leslie et al. 2004). Several F. verticillioides strains were isolated from finger millet (Eleusine coracana), and these strains have been shown to produce high levels of fumonisins, a mycotoxin produced by some species within the $F$. fujikuroi species complex (Saleh et al. 2012). The colonization of crops by mycotoxin-producing members of the genus Fusarium can result in extensive grain contamination, and can adversely affect animal and human health, subsequently leading to mycotoxicosis (Leslie and Summerell 2006; Petrovic et al. 2013).
The genus Panicum originated in Africa and currently includes approximately 500 species. Of all species, Panicum maximum Jacq is most prominent owing to its role as a productive forage grass commonly found in Brazilian markets (Araújo et al. 2013). Recently, endophytic fungi that naturally colonize and induce asymptomatic infection in the stalk of $P$. maximum were isolated from different locations in Brazil (Maia et al. 2018). Fusarium strains isolated from $P$. maximum (cv. Mombaça) had considerable morphological similarity with $F$. verticillioides, which is a widely known pathogen of maize that causes root, stalk and ear rot diseases (Leslie and Summerell 2006). In this study, we aimed to identify and characterize Fusarium strains isolated from $P$. maximum and to test their potential as maize pathogens.

\section{Material and methods}

Fungal isolates

In this study, we performed the experiments with three strains of Fusarium that were isolated during an earlier study by Maia et al. (2018). Samples were collected from the asymptomatic plants of $P$. maximum (cv. Mombaça) cultivated in the Empresa Brasileira de Pesquisa Agropecuária Gado de Leite experimental field, Coronel Pacheco, Minas Gerais, Brazil. Single spore cultures of the fungal strains were cryopreserved and deposited in the mycological collection of Universidade Federal de Pernambuco, Recife, Brazil, under the following culture accession numbers: CMM 3363, CMM 3557, and CMM 3558.

\section{DNA extraction, amplification and sequencing}

All the strains were cultured in $100 \mathrm{~mL}$ of $2 \%(\mathrm{w} / \mathrm{v})$ malt extract broth (HiMedia Laboratories, Mumbai, India) for $72 \mathrm{~h}$ on a rotary mixer under continuous agitation at $100 \mathrm{rpm}$. Genomic DNA was isolated from fresh mycelia using the Wizard ${ }^{\circledR}$ Genomic DNA purification kit (Promega, USA) according to the manufacturer's instructions. The DNA concentrations were estimated using agarose gel electrophoresis, and visual comparison was performed using a $1 \mathrm{~kb}$ DNA ladder (Axygen, USA). 
Partial DNA sequences from the $E F-1 \alpha$ gene were amplified and sequenced using the primers EF-1 (5'-ATGGGTAAGGARGACAAGAC-3') and EF-2 (5'-GGARGTACCAGTSATCATG-3') (O'Donnell et al. 1998a). In addition, the RPB2 gene encoding the second largest subunit of RNA polymerase II was amplified and sequenced using the primers 5F2 (5'-GGGGWGAYCAGAAGAAGGC) and 7cR (5'-CCCATRGCTTGYTTRCCCAT) (Liu et al. 1999; Sung et al. 2007). The PCR were performed using the GoTaq Colorless Master Mix kit (Promega, USA). The amplification conditions were: $94{ }^{\circ} \mathrm{C}$ for $90 \mathrm{~s}, 35$ cycles at $94{ }^{\circ} \mathrm{C}$ for $30 \mathrm{~s}, 62^{\circ} \mathrm{C}$ for $45 \mathrm{~s}$ and $72{ }^{\circ} \mathrm{C}$ for $1 \mathrm{~min}$, followed by a cycle at $72{ }^{\circ} \mathrm{C}$ for $5 \mathrm{~min}$ for $E F-1 \alpha$ gene; $94{ }^{\circ} \mathrm{C}$ for $90 \mathrm{~s}$, 40 cycles at $94{ }^{\circ} \mathrm{C}$ for $30 \mathrm{~s}, 55^{\circ} \mathrm{C}$ at $90 \mathrm{~s}$ and $72{ }^{\circ} \mathrm{C}$ for $2 \mathrm{~min}$, followed by a cycle at $72{ }^{\circ} \mathrm{C}$ for $5 \mathrm{~min}$ for $R P B 2$ gene. The amplified fragments were purified using the Wizard $\AA$ SV Gel and the PCR Clean-Up System (Promega, USA). For the sequencing reactions, the samples were prepared using the Big Dye V3.1 kit (Applied Biosystems, USA), as recommended by the manufacturer, and analyzed with 3500xL DNA Genetic Analyzer (Applied Biosystems, USA).

\section{Phylogenetic analysis}

The quality of the nucleotide consensus sequences was assessed, and the sequences were assembled using SeqAssem (Hepperle 2004). The edited sequences were compared with those retrieved from the GenBank database of the National Center for Biotechnological Information, using the Basic Local Alignment Search Tool (BLAST) program (http://http://www.ncbi.nlm.nih. gov/cgi-bin/BLAST/). The sequences obtained in this study were deposited in the GenBank database under the following accession numbers $E F-1 \alpha$ : KY490537 (CMM 3557), KY490538 (CMM 3558), KY490539 (CMM 3363); RPB2: MT188557 (CMM 3557), MT188558 (CMM 3558), MT740293 (CMM 3363). The sequences of the reference strains of species belonging to the FFSC that were available in the GenBank database were used for the analyses (Online Resource 1). Multiple sequence alignment of each gene was performed using Clustal $\mathrm{W}$ and were further evaluated using MEGA X (Kumar et al. 2018). The maximum Parsimony (MP) analysis was performed for each locus separately and the combined dataset $(E F$ -
$1 \alpha+R P B 2)$ using the Tree Bisection and Reconstruction software. The consistency and retention indices were estimated as a measure of homoplasy in the dataset. The most suitable substitution model was determined based on the lowest Akaike Information Criterion (AIC) using MEGA X (Kumar et al. 2018). The maximum likelihood (ML) analyses were conducted using $\mathrm{TN} 93+\mathrm{G}$ for the combined dataset $(E F-1 \alpha+R P B 2)$. Initially, the analysis was performed by generating a tree using the BioNJ tool, and the subsequent heuristic search was conducted with the Nearest-NeighbourInterchange option. The robustness of the topology was assessed using 1000 bootstrap replicates that were run by the MP and ML methods. Fusarium inflexum and Fusarium oxysporum were used as the outgroups for this analysis.

\section{Examination of morphological characters}

Morphological characterization was performed according to the methods described by Leslie and Summerell (2006). The macroscopic characteristics of fungal growth were evaluated based on the observation of the potato dextrose agar (PDA) medium. The morphology and colour of the colonies were noted after the cultures were maintained for $10 \mathrm{~d}$ at $20{ }^{\circ} \mathrm{C}$ and $12 \mathrm{~h}$ photoperiodic conditions maintained using continuous fluorescent light. For the evaluation of the mycelial growth rates, the cultures were kept in the dark at $25^{\circ} \mathrm{C}$ and examined after $4 \mathrm{~d}$. The micromorphological characteristics were examined after cultivating the strain on synthetic nutrient-poor agar medium (SNA; Nirenberg 1976) along with sterilized carnation leaves for $14 \mathrm{~d}$ at $25^{\circ} \mathrm{C}$ under a $12 \mathrm{~h}$ photoperiod maintained using cool white fluorescent light.

Identification of mating types by PCR

The mating type of each strain was determined through PCR by using primers specific to the mating idiomorphs, with the primer sets Gfmatla and Gfmatlb for MAT1-1, and Gfmat2c and Gfmat2d for MAT1-2 (Steenkamp et al. 2000). The PCR were performed using the GoTaq Colorless Master Mix kit (Promega, USA). The amplification conditions were: $95{ }^{\circ} \mathrm{C}$ for $90 \mathrm{~s}, 30$ cycles at $95{ }^{\circ} \mathrm{C}$ for $30 \mathrm{~s}, 55^{\circ} \mathrm{C}$ for $45 \mathrm{~s}$, and $72{ }^{\circ} \mathrm{C}$ for $1 \mathrm{~min}$, followed by a cycle at $72^{\circ} \mathrm{C}$ for $5 \mathrm{~min}$ for both MAT regions. The amplified fragments were evaluated in agarose gel stained with GelRed under UV 
light and recorded using the Gel Logic 200 imaging system (Kodak, USA).

\section{Pathogenicity test}

The seeds of the maize hybrid DKB 390 were surface treated with $2 \%(\mathrm{v} / \mathrm{v}) \mathrm{NaClO}$ for $10 \mathrm{~min}$ and rinsed in sterile distilled water. One seed was sown at a depth of $1 \mathrm{~cm}$ in sterilized soil contained in $15 \mathrm{~L}$ pots and cultivated in the greenhouse under natural photoperiodic conditions at $30{ }^{\circ} \mathrm{C}$ until the seedlings reached the phonological stage V7. The stalks were inoculated at approximately $10 \mathrm{~cm}$ above the soil level by inserting a sterile toothpick tip overgrown with mycelia of the Fusarium strains CMM 3363, CMM 3557, CMM 3558 , and one positive control - $F$. verticillioides strain CMM 3131 (Scauflaire et al. 2012; Costa et al. 2019). Sterile toothpicks without a fungal inoculum were included as a negative control. The experimental setup included five replication for each treatment in a completely randomized blocks design. The plants were collected $30 \mathrm{~d}$ after inoculation, and the stalks sectioned longitudinally for the examination of the necrotic region around the point of insertion.

\section{Results}

Phylogeny

The phylogenetic trees for each locus were constructed separately, and single trees were generated for $E F-1 \alpha$ (Online Resource 2) and RPB2 (Online Resource 3). The fungal strains CMM 3363, CMM 3557 and CMM 3558 formed a monophyletic clade. The tree for the combined dataset $(E F-1 \alpha+R P B 2)$ of MP and ML contained the same major clades as those observed in the MP tree (Fig. 1). The strains CMM 3363, CMM 3557 and CMM 3558 formed a well-supported monophyletic group. Therefore, these were considered to form a new phylogenetic species belonging to the FFSC.

Taxonomy

Fusarium gigantea M.P. Melo, S.S.C. Guimarães \& P.G. Cardoso, sp. nov.; Fig. 2.

MycoBank: MB 836349.

Etymology: Refers to the size of the macroconidia.
Holotype: Brazil, State of Minas Gerais, municipality of Coronel Pacheco, experimental field of

the Empresa Brasileira de Pesquisa Agropecuária Gado de Leite; dried culture on PDA, isolated from asymptomatic stem of Panicum maximum, 2015, collected by Natalia Costa Maia - VIC 47412.

Ex-type culture, CMM 3557. GenBank accession numbers: $E F-1 \alpha=\mathrm{KY} 490537 ; R P B 2=\mathrm{MT} 188557$.

Colonies on PDA showing radial mycelial growth rates of $3.2 \mathrm{~mm} \mathrm{day}^{-1}$ at $20{ }^{\circ} \mathrm{C}$ in the dark. Colony color on PDA violet to salmon (Fig. 2a). Reverse pigmentation on PDA purple (Fig. 2b). Aerial mycelium generally abundant, loose to sometimes dense floccose, white on SNA (Fig. 2c). Reverse pigmentation on SNA yellow in the middle and a yellowishwhite at the margins (Fig. 2d). Aerial conidiophores erect, occasionally prostrate, formed abundantly, sporulation by simple or branched monophialidic (Fig. 2e) and polyphialidic conidiogenous cells (Fig. 2f). Phialides cylindrical, $9.725 .3 \mu \mathrm{m} \times 1.33 .2 \mu \mathrm{m}$, producing microconidia chain and held in false heads (Fig. 2g). Chlamydospores solitary or in chains, formed abundantly in hyphae, measured 3.3-12 $\mu \mathrm{m}$ (Fig. 2h-i). Microconidia ovoidal, mostly 0 -septate, from $4.8 \quad 12.3 \mu \mathrm{m} \times 1.7 \quad 2.8 \mu \mathrm{m}$, occasionally $1-2$ septate (Fig. 2j-1). Sporodochial conidiophores irregularly branched or unbranched, phialides producing conidia that accumulate into cream to orange-colored masses on the carnation leaf. Sporodochial conidia, mostly falcate, contained a few pronounced apical cells and foot-like basal cells, 3-11 septate, 11.2$107.5 \mu \mathrm{m} \times 1.9-5.0 \mu \mathrm{m}$ (Fig. 2k-1).

Additional specimens examined: BRAZIL, Minas Gerais, Coronel Pacheco, isolated from the asymptomatic stem of Panicum maximum, 2015, collected by Natalia Costa Maia, CMM 3558; BRAZIL, Minas Gerais, Coronel Pacheco, isolated from the asymptomatic stem of Panicum maximum, 2015, collected by Natalia Costa Maia, CMM 3363.

Phylogenetic differentiation: This species is differentiated from other species of the Fusarium fujikuroi complex by phylogenetic analyses of its $E F-1 \alpha$ and $R P B 2$ gene sequences and the concatenate dataset $(E F-1 \alpha+R P B 2)$.

Morphological differentiation: This species is morphologically different from the other species of the FFSC due to the production of long macroconidia with the presence of a 3-11 septa. 
Fig. 1 Maximum parsimony best-tree phylograms for the $E F$ $1 \alpha+R P B 2$ sequences showing relationships among species belonging to the FFSC complex. Strains from this study are indicated in bold. Branch lengths are proportional to the distance. The numbers on the nodes indicate the MP and ML bootstrap values above $70 \%$ (MP/ML). Ex-type and ex-neotype strains are indicated by $\mathrm{T}$ and NT, respectively

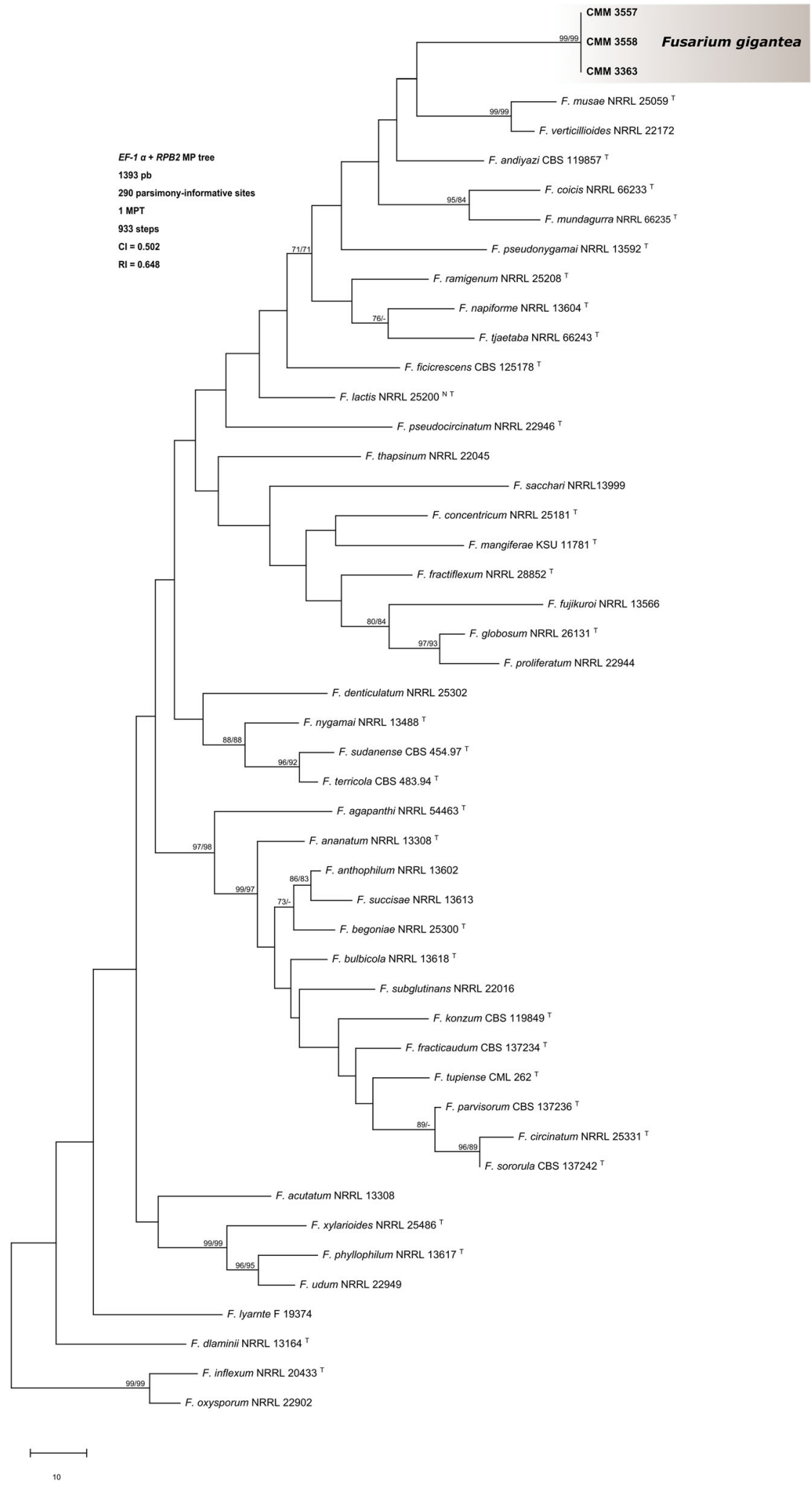



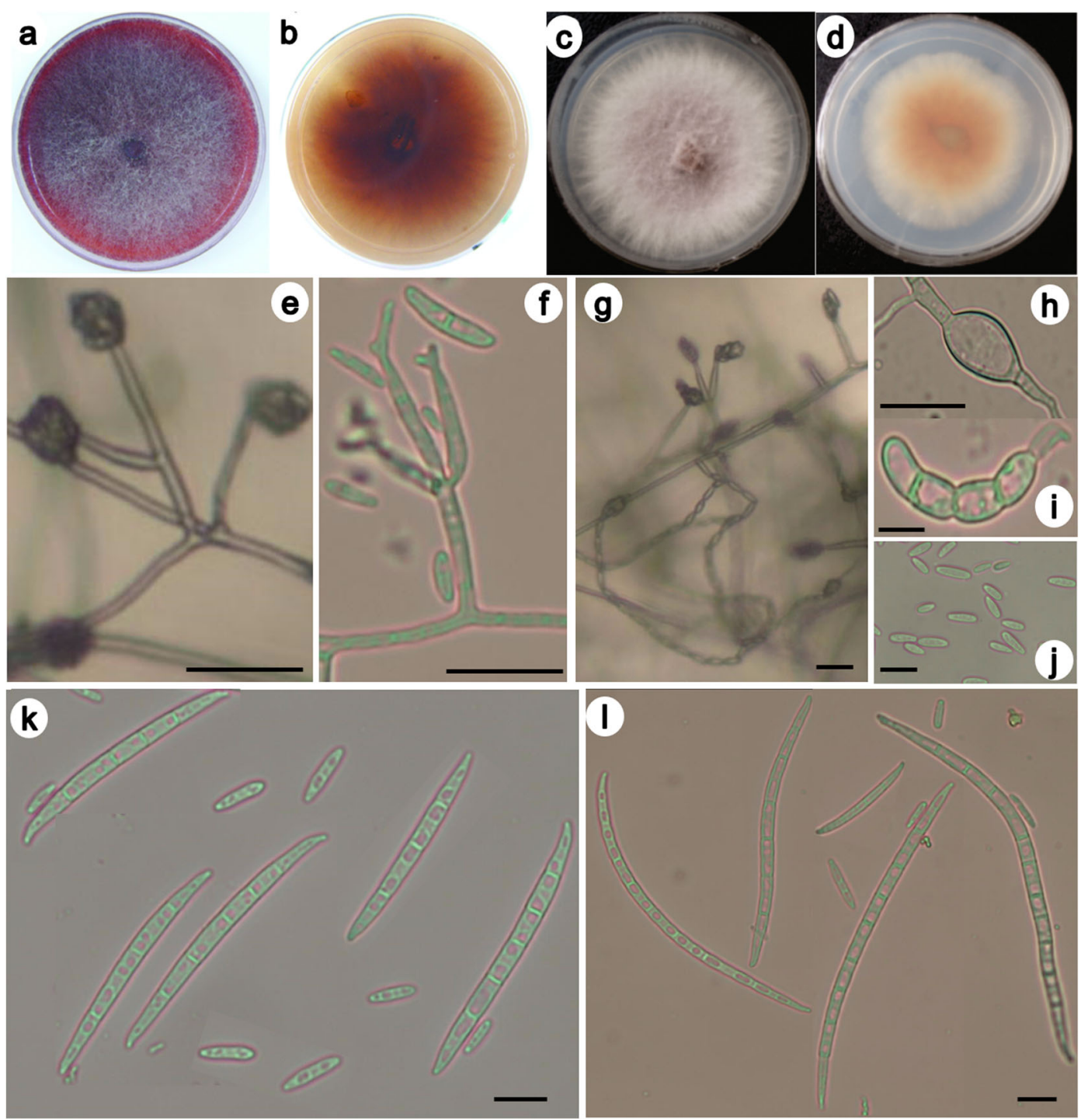

Fig. 2 Morphology of $F$. gigantea: a. Front colony on PDA medium. b. Reverse colony on PDA medium. c. Front colony on SNA medium. d. Reverse colony on SNA medium. e. Long monophialide. f. Polyphialides in the aerial mycelium. g. Long

\section{Identification of mating types}

All strains were identified as MAT1-2 (Online Resource 4). Therefore, it was not possible to perform the sexual compatibility tests between strains.

\section{Pathogenicity test}

After $30 \mathrm{~d}$ of inoculation, the maize stalks were sectioned longitudinally, and the necrotic region that developed around the insertion point was observed in monophialides producing microconidia in false heads and chains. h-i. Chlamydospores. j. Microconidia. k-l. Macro and microconidia. Scale bars $=10 \mu \mathrm{m}$

the stalk samples inoculated with the positive control - F. verticillioides (CMM 3131), and with each of the three $F$. gigantea strains (CMM 3558, CMM 3363, and CMM 3557) (Fig. 3a-d). Furthermore, a region of dark tissue was observed around the insertion point of the sterile toothpick in the negative control (Fig. 3e). Koch's postulates were fulfilled by reisolation of the pathogen from inoculated plants, and the same morphological characteristics were observed in the newly inoculated maize samples as in those inoculated originally. 

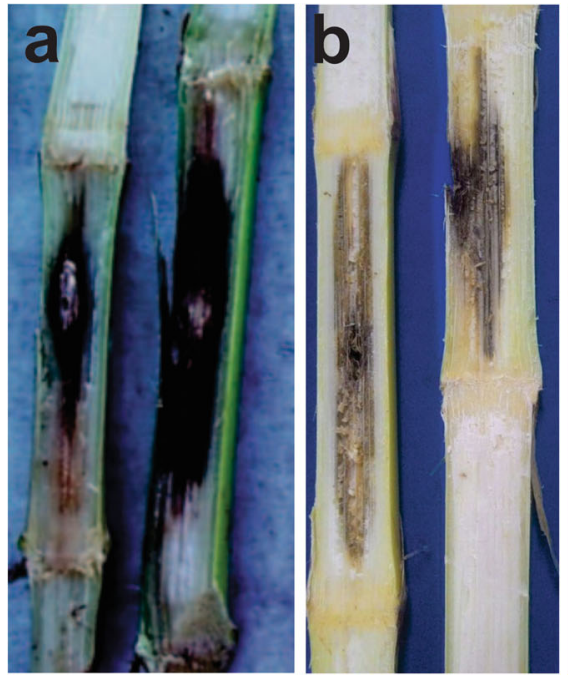

Fig. 3 Longitudinal sections of maize stalks with necrotic lesions around the insertion point of Fusarium infested toothpicks 30 days after inoculation. a. Positive control $F$. verticillioides (CMM

\section{Discussion}

This study provides the first report of a new phylogenetic species, $F$. gigantea, belonging to the FFSC that causes an asymptomatic infection in $P$. maximum and stalk rot in maize. Therefore, this species can be considered a potential grass pathogen and will be of particular relevance in maize cultivation in Brazil. The identification of pathogens is generally based on the evaluation of their morphological characteristics. Consequently, the possibility of erroneous identifications remains. Therefore, it is necessary to conduct a systematic survey in maize plantations in the main regions of production and identify the potential pathogens using the phylogenetic species recognition (PSR) methods (Taylor et al. 2000). The sequencing of $E F-1 \alpha$ gene has been denoted as the marker of choice for the identification of species belonging to the FFSC using PSR methods as it is a singlecopy gene containing significant genetic information on closely related species (Geiser et al. 2004). EF-1 $\alpha$ has been recommended as a standard in Fusarium species identification methods, particularly in cases in which the morphological and mating tests are insufficient for diagnosis (Leslie and Summerell 2006; Kvas et al. 2009; Stielow et al. 2015; Al-Hatmi et al. 2016). Besides EF$1 \alpha$, other genes, such as $R P B 2$ and the beta-tubulin gene, have been used for the establishment of species phylogeny in the FFSC owing to the reasonable degree of sequence variation among multiple taxa (Moussa et al. 2017).

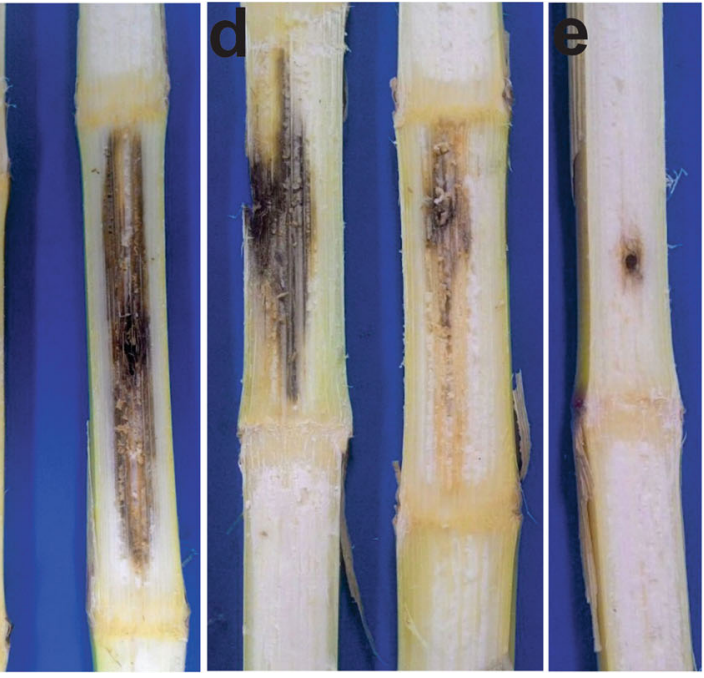

3131). b. F.gigantea (CMM 3558). c. F. gigantea (CMM 3363). d. F. gigantea (CMM 3557). e. Negative control with sterile toothpick insertion

Based on the multigenic analysis, the species of the FFSC are grouped into three major groups, called African, Asian, and American clades (O'Donnell et al. 1998b). The authors resorted to biogeography to explain the origin of these groups. The African clade is the group that represents the greatest diversity of species in the F. fujikuroi complex, which produce chlamydospores and pseudochlamydospores - characteristics not shared by the species of the Asian and American clades (Leslie and Summerell 2006; Kvas et al. 2009). In our study, F. gigantea exhibits morphological characteristics that are considerably similar to $F$. nygamai, which belongs to African clade, like the formation of microconidia in chains, polyphialides, and production of chlamydospores. However, the presence of macroconidia with up to 11 septa is an important morphological marker to distinguish this new species, since that species of the FFSC produce macroconidia with 3-7 septa (Leslie and Summerell 2006).

Although the biological concept may also help for delimiting Fusarium species (Leslie and Summerell 2006), sometimes it cannot be applied. For instance, it is impossible to perform a sexual compatibility test between strains of the same mating type or sterile strains, as it has been observed in $F$. verticillioides and $F$. thapsinum, if the laboratory crossing conditions have not yet been optimized, as occur for $F$. andiyazi, and if the tester strains are not 
available to make the crosses required for identification(Summerell et al. 2003). In our study, all strains were identified as MAT1-2, and the intercrossing between themselves was impossible. Therefore, we identified the new species $F$. gigantea based on phylogenetic and morphological species approaches.

Researches have shown the existence of species of FFSC obtained from grasses as endophytes, but when inoculating in cultivated grasses caused diseases. $F$. sacchari strains, obtained from asymptomatic wild rice in Northern Australia, when inoculated in rice, sorghum, and corn plants, reduced seed emergence and seedling damping-off (Petrovic et al. 2013). Endophytic $F$. fujikuroi strains from Echinochloa sp. in California induced Bakanae symptoms in rice plants (Carter et al. 2008).

In Brazil, Brachiaria and Panicum grasses are used as forage intercrops and cover plants in non-tillage systems. These plants have been reported to harbour several Fusarium species (Melo 2014; Carmo 2017). Fungal species such as $F$. andiyazi, $F$. proliferatum, $F$. thapsinum, and $F$. verticillioides have been isolated from Brachiaria seeds with asymptomatic infection. Moreover, pathogenicity tests have revealed that these species can cause stalk rot in maize, sorghum and millet (Melo 2014). Certain hosts serve as inoculum reservoirs of different pathogens, rendering them as a threat to economically important crops. Furthermore, mycotoxin-producing species are a potential threat to cultivated grasses (Leslie et al. 2004).

We reported a new phylogenetic species within the FSSC in Panicum. Carmo (2017) previously reported other species complexes that are associated with $P$. maximum, such as the Fusarium chlamydosporum species complex, Fusarium incarnatum-equiseti species complex and Fusarium graminearum species complex. In Brazil, there are several types of grass species that are used for biomass production and for grazing. Therefore, further studies should be undertaken to investigate the diverse types of Fusarium species associated with tropical grasses to recognize the potential pathogens that might inhabit natural ecosystems (Walsh et al. 2010).

Several Fusarium species are pathogenic to maize, such as $F$. verticillioides, $F$. graminearum, $F$. proliferatum, F. subglutinans, (Leslie and Summerell 2006), Fusarium culmorum, Fusarium crookwellense, Fusarium avenaceum, and Fusarium temperatum (Lew et al. 1996; Bottalico 1998; Scauflaire et al. 2011). In our study, the
Fusarium strains CMM3363, CMM3557, and CMM3558 induced the development of maize stalk rot symptoms, similar to those induced by $F$. crookwellense, $F$. culmorum, $F$. graminearum, and $F$. verticillioides upon inoculation with a pathogen-infested toothpick (Scauflaire et al. 2012). The findings of this study contribute to the identification of a possible new etiological agent that is capable of causing stalk rot in maize, and it might further contribute to breeding programs for the identification and development of resistant genotypes. However, the data on the geographical distribution, frequency, host range and epidemiology of the $F$. gigantea and its potential risk as a mycotoxin producer are not yet available. Therefore, further experiments on the identification of pathogenic species that affect economically important crops and are associated with grasses should be undertaken, and species that act as endophytes should be considered as well.

Acknowledgments The authors thank the Fundação de Amparo à Pesquisa do Estado de Minas Gerais (FAPEMIG), the Coordenação de Aperfeiçoamento de Pessoal de Nível Superior (CAPES), and the Conselho Nacional de Desenvolvimento Científico e Tecnológico (CNPq) for providing financial support.

\section{Compliance with ethical standards}

Ethical approval This manuscript is original and not published elsewhere. The authors have discussed the results and read and approved the final version of this manuscript. The authors also confirm that there are no ethical issues associated with the publication of this manuscript.

Conflict of interest The authors have no conflict of interest to declare.

Research involving human participants and/or animals This study does not include experiments involving human participants or animals.

\section{References}

Al-Hatmi, A. M., Meis, J. F., \& de Hoog, G. S. (2016). Fusarium: Molecular diversity and intrinsic drug resistance. PLoS Pathogens, 14, e1005464.

Araújo, L. C., Santos, P. M., Rodriguez, D., Pezzopane, J. R. M., Oliveira, P. P. A., \& Cruz, P. G. (2013). Simulating Guinea grass production: Empirical and mechanistic approaches. Agronomy Journal, 105, 61-69.

Bottalico, A. (1998). Fusarium diseases of cereals: Species complex and related mycotoxin profiles, in Europe. Journal of Plant Patholology, 80, 85-103. 
Busby, P. E., Ridout, M., \& Newcombe, G. (2016). Fungal endophytes: Modifiers of plant disease. Plant Molecular Biology, 90, 645-655.

Carmo, F. S. (2017). Espécies de Fusarium associadas a gramineas forrageiras. Dissertation: Universidade Federal de Lavras.

Carter, L. L. A., Leslie, J. F., \& Webster, R. K. (2008). Population structure of Fusarium fujikuroi from California rice and water grass. Phytopathology, 98, 992-998.

Costa, M. M., Melo, M. P., Guimarães, E. A., Veiga, C. M. O., Carmo Sandin, F., Moreira, G. M., Costa, S. S., \& Pfenning, L. H. (2019). Identification and pathogenicity of Fusarium species associated with pokkah boeng of sugarcane in Brazil. Plant Pathology, 68, 1350-1360.

Geiser, D. M., Jimenez-Gasco, M. D., Kang, S. C., et al. (2004). FUSARIUM-ID v. 1.0: A DNA sequence database for identifying Fusarium. European Journal of Plant Patholology, 110, 473-479.

Górzyńska, K., Wegrzyn, E., Sandecki, R., \& Lembicz, M. (2019). Endophytic fungi and latent pathogens in the sedge Carex secalina Cyperaceae, a critically endangered species in Europe. Plant Protection Science, 55, 102-108.

Hepperle, D. (2004). SeqAssem@: Win32-Version. A sequence analysis tool contig assembler and trace data visualization tool for molecular sequences. http://www.sequentix.de Accessed 25 July 2017.

Kumar, S., Stecher, G., Li, M., Knyaz, C., \& Tamura, K. (2018). MEGA X: molecular evolutionary genetics analysis across computing platforms. Molecular Biology and Evolution, 35, $1547-1549$.

Kvas, M., Marasas, W. F. O., Winglfield, B. D., Winglfield, M. J., \& Steenkamp, E. T. (2009). Diversity and evolution of Fusarium species in the Gibberella fujikuroi complex. Fungal Diversity, 1, 1-21.

Laurence, M. H., Walsh, J. L., Shuttleworth, L. A., et al. (2015). Six novel species of Fusarium from natural ecosystems in Australia. Fungal Diversity, 77, 349-366.

Leslie, J. F., \& Summerell, B. A. (2006). The fusarium laboratory manual. Ames: Blackwell Publishing, USA.

Leslie, J. F., Zeller, K. U., Logrieco, A., Mulè, G., Moretti, A., \& Ritieni, A. (2004). Species diversity of and toxin production by Gibberella fujikuroi species complex strains isolated from native prairie grasses in Kansas. Applied and Environmental Microbiology, 70, 2254-2262.

Lew, H. J., Chelkowski, J., Pronczuk, P., \& Edinger, W. (1996). Occurrence of the mycotoxin moniliformin in maize (Zea mays L.) ears infected by Fusarium subglutinans (Wollenweber and Reinking) Nelson et al. Food Additives and Contaminants, 13, 321-324.

Liu, Y. J., Whelen, S., \& Hall, B. D. (1999). Phylogenetic relationships among ascomycetes: Evidence from an RNA polymerase II subunit. Molecular Biology and Evolution, 16, 1799-1808.

Maia, N. C., Souza, P. N. C., Godinho, B. T. V., et al. (2018). Fungal endophytes of Panicum maximum and Pennisetum purpureum: Isolation, identification, and determination of antifungal potential. Revista Brasileira de Zootecnia, 47, e20170183.

Melo, M. P. (2014). Espécies biológicas e filogenéticas do complexo Fusarium fujikuroi. Thesis Universidade Federal de Lavras.
Moussa, T. A. A., Al-Zahrani, H. S., Kadasa, N. M. S., Ahmed, S. A., de Hoog, G. S., \& Al-Hatmi, A. M. S. (2017). Two new species of the Fusarium fujikuroi species complex isolated from the natural environment. Antonie Van Leeuwenhoek, $110,819-832$.

Nirenberg, H. I. (1976). Untersuchungen Über die morphologische und biologische Differenzierung in der Fusarium Sektion Liseola. Mitteilungen der Biologischen Bundesanstalt für Land- und Forstwirtschaft, 169, 1-117.

O’Donnell, K., Kistler, H. C., Cigelnik, E., \& Ploetz, R. C. (1998a). Multiple evolutionary origins of the fungus causing Panama disease of banana: Concordant evidence from nuclear and mitochondrial gene genealogies. Proceedings of the National Academy of Sciences of the United States of America, 95, 2044-2049.

O’Donnell, K., Cigelnik, E., \& Nirenberg, H. I. (1998b). Molecular systematics and phylogeography of the Gibberella fujikuroi species complex. Mycologia, 90, 465493.

Petrovic, T., Burgess, L. W., Cowie, I., Warren, R. A., \& Harvey, P. R. (2013). Diversity and fertility of Fusarium sacchari from wild rice Oryza australiensis in northern Australia, and pathogenicity tests with wild rice, rice, sorghum and maize. European Journal of Plant Pathology, 136, 773-788.

Photita, W., Lumyong, S., Lumyong, P., McKenzie, E., \& Hyde, K. D. (2004). Are some endophytes of Musa acuminata latent pathogens? Fungal Diversity, 16, 131-140.

Saleh, A. A., Esele, J. P., Logrieco, A., Ritieni, A., \& Leslie, J. F. (2012). Fusarium verticillioides from finger millet in Uganda. Food Additives and Contaminants, 29, 1-8.

Scauflaire, J., Mahieu, O., Louvieaux, J., Foucart, G., Renard, F., \& Munaut, F. (2011). Biodiversity of Fusarium species in ears and stalks of maize plants in Belgium. European Journal of Plant Pathology, 131, 59-66.

Scauflaire, J., Gourgue, M., Callebaut, A., \& Munaut, F. (2012). Fusarium temperatum, a mycotoxin-production pathogen of maize. European Journal of Plant Pathology, 133, 911-922.

Steenkamp, E. T., Wingfield, B. D., Coutinho, T. A., et al. (2000). PCR-based identification of MAT-1 and MAT-2 in the Gibberella fujikuroi species complex. Applied and Environmental Microbiology, 66, 4378-4382.

Stielow, B., Le'vesque, C. A., Seifert, K. A., et al. (2015). One fungus, which genes? Assessing primers for potential universal secondary DNA barcodes. Persoonia, 35, 242-263.

Summerell, B. A., Salleh, B., \& Leslie, J. F. (2003). A utilitarian approach to Fusarium identification. Plant Disease, 87, 117128.

Sung, G. H., Sung, J. M., Hywel-Jones, N. L., \& Spatafora, J. W. (2007). A multi-gene phylogeny of Clavicipitaceae (Ascomycota, fungi): Identification of localized incongruence using a combinational bootstrap approach. Molecular Phylogenetics and Evolution, 44, 1204-1223.

Swett, C. L., \& Gordon, T. R. (2012). First reports of grass species Poaceae as naturally occurring hosts of the pine pathogen Gibberella circinata. Plant Disease, 96, 908-908.

Swett, C. L., Porter, B., Fourie, G., Steenkamp, E. M., Gordon, T. R., \& Wingfield, M. J. (2014). Association of the pitch canker pathogen Fusarium circinatum with grass hosts in commercial pine production areas South Africa. Southern Forest, 76, 161-168. 
Taylor, J. W., Jacobson, D. J., Kroken, S., Kasuga, T., Geiser, D. M., Hibbett, D. S., \& Fisher, M. C. (2000). Phylogenetic species recognition and species concepts in fungi. Fungal Genetics Biology, 31, 21-32.

Walsh, J. L., Laurence, M. H., Liew, E. C. Y., Sangalang, A. E., Burgess, L. W., Summerell, B. A., \& Petrovic, T. (2010).
Fusarium: Two endophytic novel species from tropical grasses of northern Australia. Fungal Diversity, 44, 149-159. Zeller, K. A., Summerell, B. A., Bullock, S., \& Leslie, J. F. (2003). Gibberella konza (Fusarium konzum) sp. nov. from prairie grasses, a new species in the Gibberella fujikuroi species complex. Mycologia, 95, 943-954. 